\title{
Regulation and functional effects of ZNT8 in human pancreatic islets
}

\author{
Bruno Lefebvre ${ }^{1,2}$, Brigitte Vandewalle ${ }^{1,2}$, Anne-Sophie Balavoine ${ }^{1,2}$, Gurvan Queniat ${ }^{1,2}$, \\ Ericka Moerman $^{1,2}$, Marie-Christine Vantyghem ${ }^{1,2,4}$, Olivier Le Bacquer ${ }^{1,2}$, Valery Gmyr ${ }^{1,2}$, \\ Valérie Pawlowski $^{1,2}$, Julie Kerr-Conte ${ }^{1,2}$ and Francois Pattou ${ }^{1,2,3}$ \\ ${ }^{1}$ Univ Lille Nord de France, F-59000 Lille, France \\ ${ }^{2}$ UMR859, Biotherapies for Diabetes, F-59000 Lille, France \\ ${ }^{3} \mathrm{CHU}$ Lille, Department of Endocrine Surgery, F-59000 Lille, France \\ ${ }^{4} \mathrm{CHU}$ Lille, Endocrinology and Metabolism, F-59000 Lille, France \\ (Correspondence should be addressed to B Lefebvre who is now at Faculty of Medicine, Univ Lille Nord de France/INSERM U859, 1 place de Verdun, \\ F59045 Lille, France; Email: bruno.lefebvre@inserm.fr)
}

\begin{abstract}
Zinc ions are essential for the formation of insulin crystals in pancreatic $\beta$ cells, thereby contributing to packaging efficiency of stored insulin. Zinc fluxes are regulated through the SLC30A (zinc transporter, ZNT) family. Here, we investigated the effect of metabolic stress associated with the prediabetic state (zinc depletion, glucotoxicity, and lipotoxicity) on ZNT expression and human pancreatic islet function. Both zinc depletion and lipotoxicity (but not glucotoxicity) downregulated ZNT8 (SLC30A8) expression and altered the glucose-stimulated insulin secretion index (GSIS). ZNT8 overexpression in human
\end{abstract}

islets protected them from the decrease in GSIS induced by tetrakis-(2-pyridylmethyl) ethylenediamine and palmitate but not from cell death. In addition, zinc supplementation decreased palmitate-induced human islet cell death without restoring GSIS. Altogether, we showed that ZNT8 expression responds to variation in zinc and lipid levels in human $\beta$ cells, with repercussions on insulin secretion. Prospects for increasing ZNT8 expression and/or activity may prove beneficial in type 2 diabetes in humans.

Journal of Endocrinology (2012) 214, 225-232

\section{Introduction}

A clear and strong relationship between zinc homeostasis and pancreatic function has been established by numerous investigations over the past decade (Jansen et al. 2009). Experimental zinc deficiency is responsible for decreased insulin secretion after glucose stimulation (Chen et al. 2000). By contrast, zinc supplementation ameliorates or prevents diabetes in several rodent models of type 1 and 2 diabetes (Taylor 2005). Alteration of zinc homeostasis seems to be also associated with type 2 diabetes (T2D) in humans (Simon \& Taylor 2001, Taylor 2005). The highest levels of zinc in the organism are found in $\beta$ cells where it plays an essential role in insulin crystallization (Emdin et al. 1980). Co-secreted zinc has also paracrine effects in pancreatic islets. Zinc is thought to be a positive regulator of K-ATP channels, which are essential for insulin secretion in response to glucose (Ishihara et al. 2003). Zinc has also suppressive effects on glucagon secretion (Bancila et al. 2004).

The intracellular zinc concentration is tightly regulated by zinc importers (ZIP/SLA39), exporters (zinc transporter (ZNT)/SLC30), and binding proteins (metallothioneins, MT) (Liuzzi \& Cousins 2004, Eide 2006, Islam \& Loots du 2007).
Current understanding of their roles is that ZIP proteins allow intracellular zinc uptake. By contrast, ZNTs are involved in zinc transport from the cytoplasm into either extracellular or intracellular membrane-limited compartments (e.g. secretory vesicles). Briefly, ZNT1 (SLC30A1) is ubiquitously expressed. It is the only transporter known to be involved in zinc efflux across the plasma membrane that confers resistance to zinc (Palmiter \& Findley 1995, Liuzzi et al. 2001, Cousins et al. 2003). ZNT5 (SLC30A5) is expressed more abundantly in pancreatic $\beta$ cells (Kambe et al. 2002). ZNT6 (SLC30A6) transports zinc from the cytoplasm into the transGolgi apparatus as well as into the vesicular compartments (Huang et al. 2002). ZNT8 (SLC30A8) is expressed specifically in $\alpha$ and $\beta$ cells (Chimienti et al. 2004, Gyulkhandanyan et al. 2008). It has been localized in the secretory granules, suggesting that ZNT8, along with ZNT5, is involved in supplying zinc for insulin storage (Chimienti et al. 2006).

The role of zinc homeostasis in T2D has been recently supported further by genome-wide association studies (GWAS). GWAS consistently reported a strong association between T2D and a nonsynonymous polymorphism (single nucleotide polymorphism rs13266634) within the SLC30A8 
gene encoding ZNT8 (Scott et al. 2007, Sladek et al. 2007, Zeggini et al. 2007). Several studies have attempted to elucidate the exact role of ZNT8 in insulin signaling. Fu et al. showed that the downregulation of ZNT8 in INS-1 cells reduced both insulin content and glucose-stimulated insulin secretion index (GSIS) while overexpression had the opposite effect (Chimienti et al. 2006, Fu et al. 2009). Surprisingly, global knockout in mice demonstrated that ZNT8 is not mandatory for glucose control (Lemaire et al. 2009, Nicolson et al. 2009, Pound et al. 2009). However, deficient mice displayed age-, gender-, and diet-dependent glucose intolerance (Lemaire et al. 2009, Nicolson et al. 2009). ZNT8 $\beta$-cellspecific knockout mice $(Z n t 8 B K O)$ have reduced expression of key $\beta$-cell transcription factors PDX1 and MAFA and of insulin-processing enzymes PC1, PC2, and CPE (Wijesekara et al. 2010). Znt8BKO islets displayed reduced first-phase GSIS and these mice are glucose intolerant. Although not always concordant, all these studies support the view that ZNT8 may influence insulin signaling in humans.

In order to gather information on zinc effects in human pancreatic islets, we first examined the expression patterns of different ZNTs and islet function under metabolic stress associated with a prediabetic state (e.g. zinc depletion, glucotoxicity, and lipotoxicity). We showed that zinc depletion and lipotoxicity downregulated ZNT8 expression, which correlated with an increase in apoptosis and a decrease in GSIS. ZNT8-overexpressing islets were protected from both zinc depletion and lipotoxicity-related impaired GSIS but not from apoptosis. In addition, we showed that zinc supplementation decreased palmitate-induced human islet cell death without restoring GSIS.

\section{Materials and Methods}

\section{Human islet processing}

Sixteen human pancreases were harvested from adult braindead donors in accordance with French Regulations and with the local Institutional Ethical Committee 'Comite d'Ethique du Centre Hospitalier Régional et Universitaire de Lille'. Pancreatic islets were isolated after ductal distension of the pancreas and digestion of the tissue with Liberase as described previously (Vantyghem et al. 2009, Kerr-Conte et al. 2010). All experiments were carried out on at least three different donors of $>80 \%$ purity.

\section{Cell culture and transfection}

Purified islets were cultured in CMRL 1066 medium (Gibco BRL, Life Technologies) containing $0 \cdot 6 \%$ free fatty acid BSA (Roche Diagnostics), penicillin $(100 \mu \mathrm{IU} / \mathrm{ml})$, and streptomycin $(100 \mu \mathrm{g} / \mathrm{ml})$. Zinc deprivation was achieved using tetrakis-(2-pyridylmethyl) ethylenediamine (TPEN $20 \mu \mathrm{M}$ ) for $18 \mathrm{~h}$.
Lipotoxicity was induced by a sodium palmitate treatment for $48 \mathrm{~h}$, using palmitate bound to fatty acid-free BSA prepared as described (Roche et al. 1999, Vandewalle et al. 2008) except that KRBB was replaced by CMRL 1066. The effective palmitate concentration was determined and adjusted to $0.33 \mathrm{mmol} / 1$ in the incubation medium (final concentration). The molar ratio of fatty acid to BSA was $\sim 5$. The effective concentration of BSA was also verified in the final dilution of palmitate and found to be about $0.6 \%$. Fatty acid-free BSA was used at the same concentration in the control condition.

Human islet transfections were performed by microporation (Microporator MP100; Digital Bio, Labtech, Paris, France) after accutase (PPA Laboratories $\mathrm{GmbH}$, Linz, Austria) pretreatment (2500 IE incubated at $37^{\circ} \mathrm{C}$ for $2 \mathrm{~min}$ ) as recently described (Lefebvre et al. 2010). Transfection experiments were performed between $18 \mathrm{~h}$ and 3 days postisolation: the program was two pulses of $1400 \mathrm{~V}, 20 \mathrm{~ms}$ with $1 \mu \mathrm{g}$ plasmid for $2500 \mathrm{IE}$ for human islets.

\section{Estimation of islet cell viability and metabolism}

Islet viability was assessed after dithizone and trypan blue staining on three aliquots of 80 IE per condition.

ATP content was measured in three aliquots of 40 IE per condition by a luminescence ATP detection assay system as described by the manufacturer (ATPlite, PerkinElmer, Courtaboeuf, France).

Insulin content and glucose-stimulated insulin secretion (GSIS)

Insulin content was assayed using an RIA kit (CIS Bio International, Gif-sur Yvette, France) in the lysates of three aliquots of 40 IE per condition. GSIS was determined by static incubations of islets for $1 \mathrm{~h}$ with low glucose $(2 \cdot 8 \mathrm{mmol} / \mathrm{l}$, basal) followed by $1 \mathrm{~h}$ with high glucose $(20 \mathrm{mmol} / \mathrm{l}$, stimulated). Stimulation indexes (GSIS), defined as the ratio of stimulated to basal insulin release, were estimated from five aliquots of 40 IE per replicate.

\section{Determination of DNA fragmentation}

The specific determination of mono- and oligonucleosomes in the cytoplasmic fraction of islet lysates (three aliquots of 160 IE per condition) was achieved by quantitative sandwich enzyme immunoassay using mouse monoclonal antibodies against DNA and histones (cell death detection ELISA kit from Roche Molecular Biochemicals).

\section{$R N A$ preparation and real-time $P C R$}

Total RNA was prepared using RNeasyMinikit (Qiagen). Purified RNA was adjusted to $1 \mu \mathrm{g} / \mu \mathrm{l}$ and its integrity was assessed with the Agilent RNA 6000 chips coupled with the Agilent 2100 Bioanalyzer (Agilent Technologies, Palo Alto, CA, USA), by visualizing the $18 \mathrm{~S}$ and $28 \mathrm{~S}$ ribosomal RNA. 

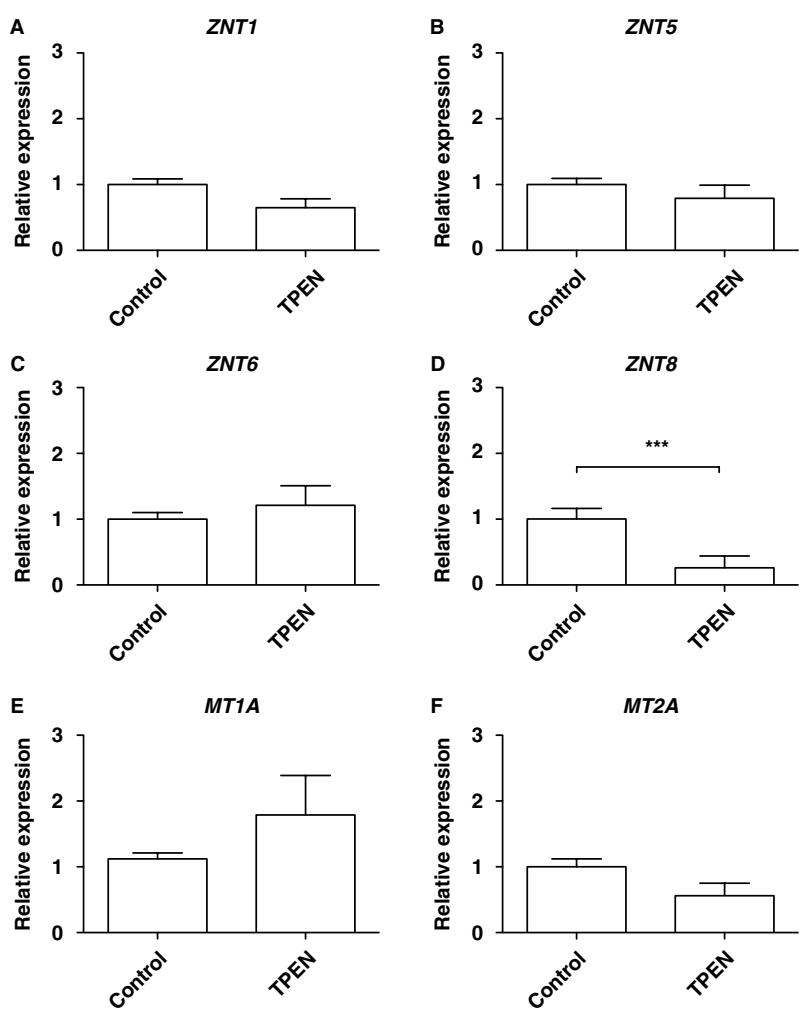

Figure 1 Zinc depletion downregulated ZNT8 expression in human pancreatic islets. Human pancreatic islets were cultivated in the absence or in the presence of $20 \mu \mathrm{mol} / \mathrm{I}$ TPEN for $18 \mathrm{~h}$. ZNT, MT1, and MT2 expressions were analyzed by real-time PCR and normalized to RPLO. Values are mean \pm S.E.M. of three different pancreases. Significant difference, ${ }^{* * *} P<0 \cdot 001$, is indicated.

Reverse transcription (RT) was performed using random hexamers as recommended by the manufacturer (Applied Biosystems). cDNAs were analyzed by PCR amplification using the TaqMan PCR master mix (Applied Biosystems) and a mix of RPLO primers and probes. The different probes were purchased from Applied Biosystems (assay on demand kit). Reactions (40 cycles) and data analysis were carried out with an ABI Prism 7700 (PerkinElmer).

\section{Statistical analysis}

Results are presented as mean \pm s.E.M. The statistical differences between the groups are analyzed with ANOVA and the Fisher's least significant difference test using Statview 4.1 software (Abacus, Berkeley, CA, USA).

\section{Results}

\section{Zinc chelation downregulated ZNT8 expression and affected} human islet functions

We first examined the effect of zinc chelation on selected ZNT expressions in human pancreatic islets. For this, islets were isolated by Liberase digestion and density gradient purification and cultured in the absence or in the presence of the zinc-chelating agent TPEN. In preliminary experiments, we found an optimal concentration of $20 \mu \mathrm{mol} / 1$ for $18 \mathrm{~h}$ (data not shown). As shown in Fig. 1, human pancreatic islets cultured in the presence of TPEN displayed no significant changes in ZNT1, ZNT5, ZNT6 as well as MT1A and $M T 2 A$ expression (Fig. 1A, B, C, E and F). We normalized expression levels to housekeeping gene RPLO, which was stable under TPEN treatment (data not shown). Interestingly, a 74\% decrease in ZNT8 expression was found. No changes in insulin and PDX1 expression were observed in these different conditions (data not shown).

We next examined human islet functions in zinc deficiency conditions. We found that TPEN treatment decreased the ATP level (55\%) and increased apoptosis (twofold) compared with control islets (Fig. 2A and B). In addition, reducing extracellular zinc concentrations resulted in a significant decrease in GSIS (1.5- vs 1.95-fold) without changing the insulin content (Fig. 2C and D). The effect of TPEN was specific as all metabolic parameters were restored upon zinc supplementation (Fig. 2A, B, C and D). No effect of zinc supplementation alone was observed (data not shown and Fig. 5).
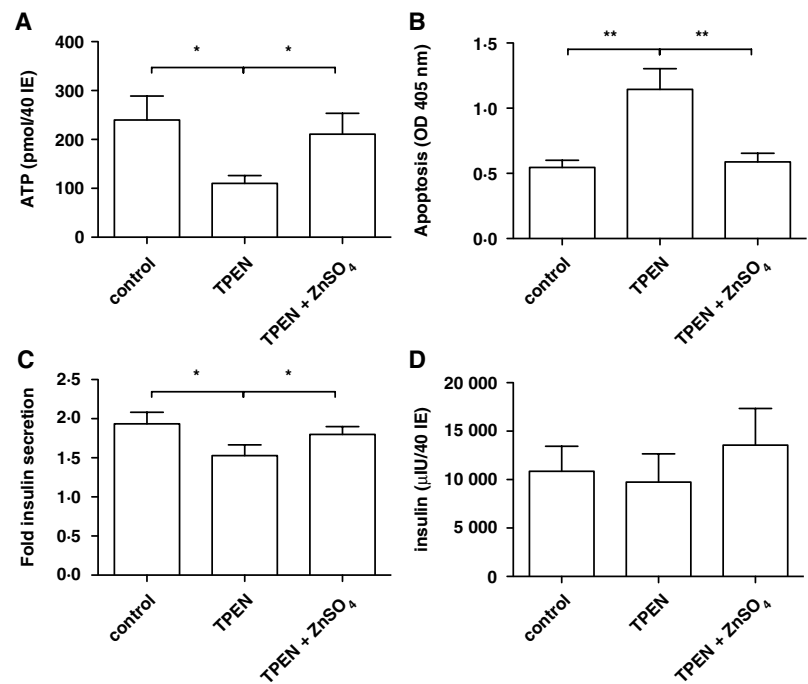

Figure 2 Zinc supplementation restored metabolic parameters of human pancreatic islets treated with TPEN. (A) ATP levels, (B) apoptosis, (C) stimulation index, and (D) intracellular insulin content were measured in human pancreatic islets supplemented or not with $40 \mu \mathrm{mol} / / \mathrm{ZnSO}_{4}$ and cultured in the absence or in the presence of $20 \mu \mathrm{mol} / \mathrm{I}$ TPEN for $18 \mathrm{~h}$. Stimulation index was calculated as the fold increase in insulin release measured in stimulation over basal levels (insulin release at $20 \mathrm{mmol} / \mathrm{l}$ over $2 \cdot 8 \mathrm{mmol} / \mathrm{I}$ glucose for $1 \mathrm{~h}$ ). Values are mean \pm S.E.M. of three different pancreases. Significant differences, ${ }^{*} P<0.05$ and $* * P<0 \cdot 01$, are indicated. 
ZNT8 overexpression restored the stimulation index in human pancreatic islets subjected to zinc chelation

The data thus far showed a correlation between ZNT8 expression and altered islet metabolic parameters in the presence of TPEN. To test a possible role of the transporter, we next transfected isolated islets by microporation with plasmids coding for GFP or GFP-ZNT8 and then, $24 \mathrm{~h}$ later, subjected them to TPEN treatment. Using this technique, more than $70 \%$ of islet cells were transfected and metabolic parameters were not altered (Lefebvre et al. 2010). Real-time PCR analysis revealed a 400-fold increase in ZNT8 expression compared with control islets (data not shown). As shown previously, control islets transfected with GFP plasmid displayed a significant decrease in ATP levels (52\%) and GSIS (1.9- vs $2 \cdot 5$-fold) as well as a twofold increase in apoptosis when subjected to TPEN treatment (Fig. 3A, B and C). This effect was not attributable to a change in the insulin
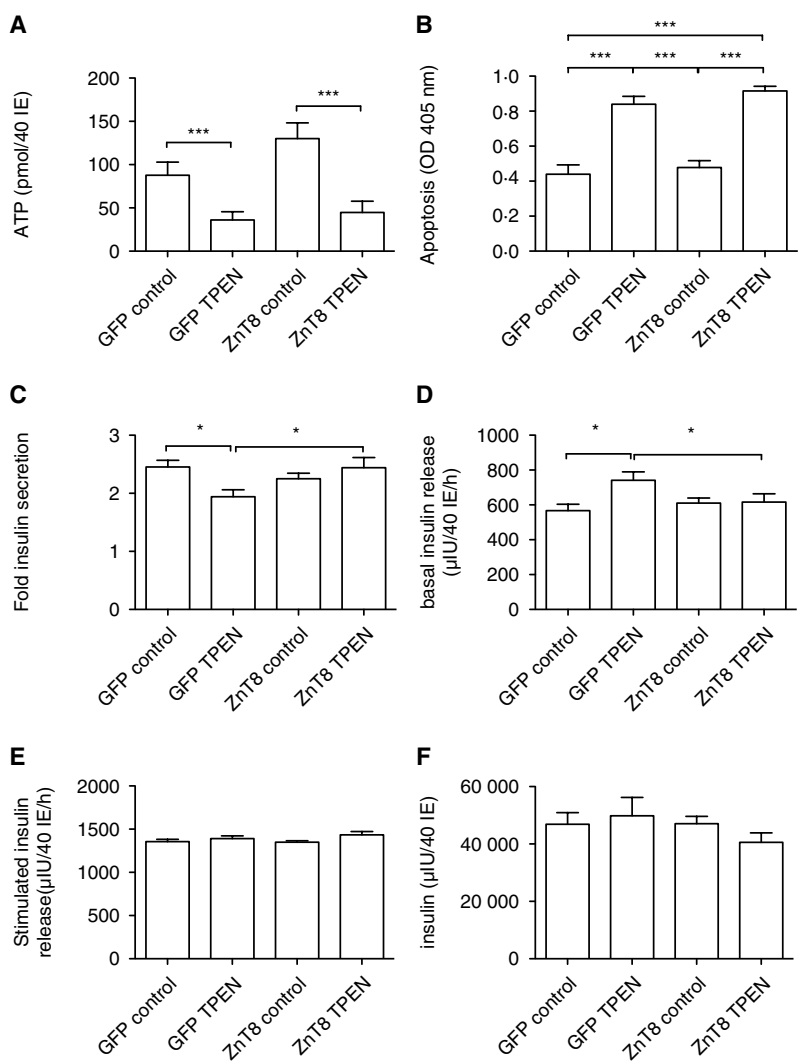

Figure 3 ZNT8 overexpression restored the stimulation index in human pancreatic islets subjected to zinc depletion. (A) ATP levels, (B) apoptosis, (C) stimulation index, (D) insulin released at $2.8 \mathrm{mmol} / \mathrm{I}$ glucose for $1 \mathrm{~h}$ (basal insulin release), (E) insulin released at $20 \mathrm{mmol} / \mathrm{l}$ glucose for $1 \mathrm{~h}$ (stimulated insulin release), and $(F)$ intracellular insulin content were measured in GFP- and ZNT8-overexpressing islets cultured in the absence or in the presence of $20 \mu \mathrm{mol} / \mathrm{l}$ TPEN for $18 \mathrm{~h}$. Stimulation index was calculated as described in Fig. 2. Values are mean \pm s.E.M. of three different pancreases. Significant differences, ${ }^{*} P<0 \cdot 05$, $* * * P<0 \cdot 001$, are indicated. storage pool but to an increase in the basal insulin release (Fig. 3C, D, E and F). Overexpressing ZNT8 did not modify the ATP level and apoptosis observed in the absence or in the presence of TPEN (Fig. 3A and B). ZNT8 overexpression had no effect on the stimulation index and insulin content in control conditions (Fig. 3C, D, E and F). However, we observed a restoration of GSIS through a decrease in basal insulin release (Fig. 3C, D, E and F).

Thus, it appears that ZNT8 overexpression restored the stimulation index by normalizing basal insulin release in the hypozincemic condition but had no effect on TPEN-induced cell death.

\section{Lipotoxicity affected human islet functions independently of extracellular zinc concentrations}

Because zinc ameliorates or prevents diabetes in several rodent models, we next investigated the relationship between extracellular zinc concentration and lipotoxicity, a common feature in T2D. We first studied selected ZNT expressions after $48 \mathrm{~h}$ of treatment with $0.33 \mu \mathrm{mol} / 1$ palmitate (mimicking lipotoxic condition), supplemented or not with $\mathrm{ZnSO}_{4}$. Real-time PCR analysis revealed that palmitate exposure did not lead to significant changes in ZNT1 and ZNT5 expression but significantly increased ZNT6 (25-30\%) expression (Fig. 4A, B and C). We also observed reduced ZNT8 expression at the mRNA (55\%) and protein levels (Fig. 4 D and Supplementary Figure 1, see section on supplementary data given at the end of this article). Zinc supplementation alone or in combination with palmitate increased ZNT1 expression and tended to increase MT1 and MT2 expression (Fig. 4A, E and F). No change in insulin gene expression was seen (data not shown).

We next investigated islet function in these different conditions. As shown in Fig. 5, incubation of islets with palmitate resulted in a significant decrease in the ATP level $(60 \%)$, insulin content $(55 \%)$, and GSIS (1·39- vs $2 \cdot 42$-fold; Fig. 5A, C and D). In addition, analysis of DNA fragmentation revealed an increase in apoptosis (Fig. 5B). Supplementation with zinc did not restore the ATP levels, insulin content, or GSIS (Fig. 5A, C and D). However, we found that zinc significantly reduced the apoptosis observed under lipotoxic condition (Fig. 5B).

Taken together, these data show that i) lipotoxicity downregulated ZNT8 expression and was correlated with altered human islet metabolic parameters and ii) zinc supplementation decreased palmitate-induced human islet cell death.

ZNT8 overexpression restored the stimulation index in human lipotoxic islets

We next investigated the effect of ZNT8 expression on human islet functions under lipotoxic conditions. As shown previously, incubation with palmitate decreased the ATP level (40\%) and increased apoptosis (twofold), and ZNT8 
A

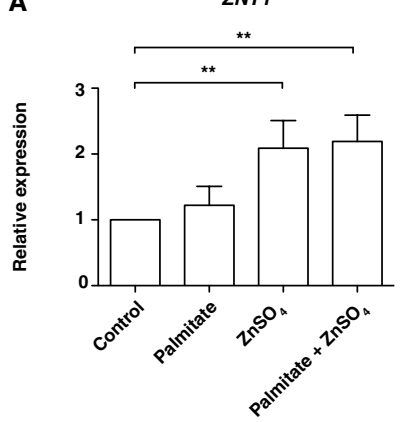

C

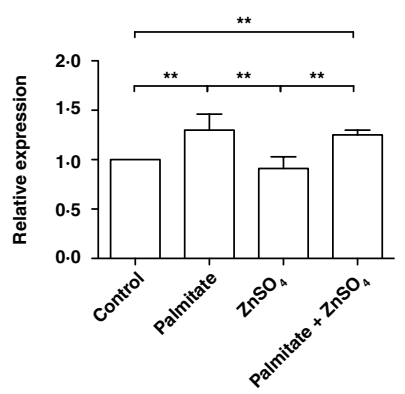

E

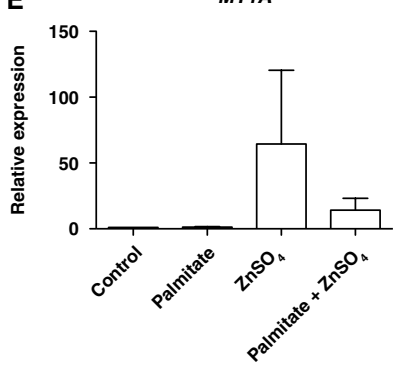

B

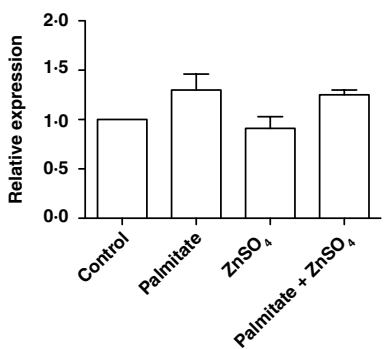

D

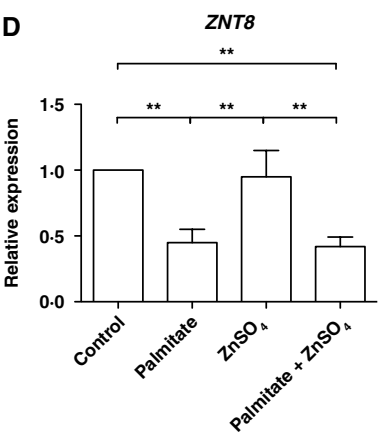

$\mathbf{F}$

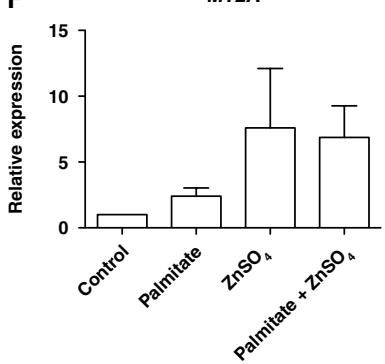

Figure 4 Lipotoxicity downregulated ZNT8 expression in human pancreatic islets. Human pancreatic islets were cultured in the absence or in the presence of $40 \mu \mathrm{mol} / / \mathrm{ZnSO}_{4}$ and in the absence or in the presence of $0.33 \mu \mathrm{mol} / \mathrm{l}$ palmitate for $48 \mathrm{~h}$. (A) ZNT1,

(B) ZNT5, (C) ZNT6, (D) ZNT8, (E) MT1A and (F) MT2A expressions were analyzed by real-time PCR and normalized to RPLO.

Values are mean \pm S.E.M. of three different pancreases.

Significant differences, ${ }^{* *} P<0 \cdot 01$, are indicated.

overexpression did not modify the observed results (Fig. 6A and B). As shown previously, palmitate exposure strongly reduced the GSIS (0.95- vs $2 \cdot 45$-fold) through an increase in basal insulin release $(2 \cdot 8$-fold; Fig. 6C). Overexpressing ZNT8 restored the GSIS by normalizing basal insulin release compared with control islets (Fig. 6C, D and E). In addition, ZNT8-overexpressing islets displayed a slight but reproducible increase in the GSIS in the presence of palmitate. Interestingly, lipotoxicity decreased the insulin content that was not modified upon ZNT8 overexpression.

Taken together, these data showed that ZNT8 overexpression restored the glucose-stimulated insulin secretion under lipotoxic conditions by normalizing the basal insulin release but had no effect on palmitate-induced cell death.

\section{Discussion}

In this study, we attempted to elucidate the role of zinc and selected ZNTs in human pancreatic islets in relation to metabolic stress associated with a prediabetic state. Converging evidence suggests that glucose and nonesterified fatty acids contribute to T2D progression through glucotoxic and lipotoxic effects on $\beta$ cells (Kahn et al. 2006). Hypozincemia is also a common feature in T2D and affects $\beta$-cell function (Taylor 2005).

We found essentially that ZNT8 is downregulated upon zinc chelation and palmitate exposure. Glucotoxicity and cytokine exposure have been shown to significantly reduce ZNT8 expression in $\beta$-cell lines (Egefjord et al. 2009, Smidt et al. 2009). However, we did not find any variation in ZNT8 expression in the presence of different glucose concentrations arguing for a specific regulation in human islets (Supplementary Figure 1). ZNT8 is also downregulated in $d b / d b$ and Akita mice at early stages of diabetes, supporting the relevance of our in vitro finding (Tamaki et al. 2009).

We next assessed the role of zinc and ZNT8 on human islet survival. We showed that zinc supplementation decreased palmitate-induced islet cell death but did not restore GSIS. However, we did not find any relationship between ZNT8
A

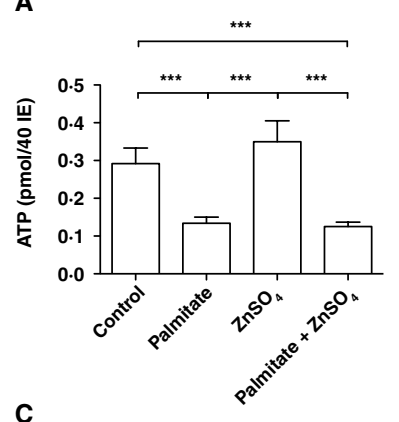

C

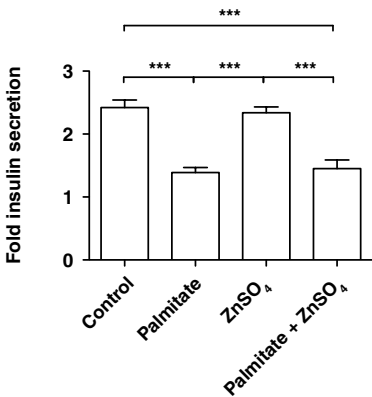

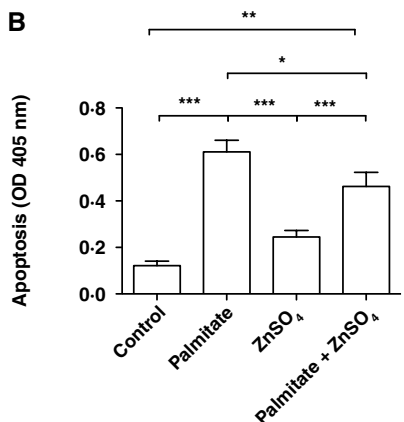

D

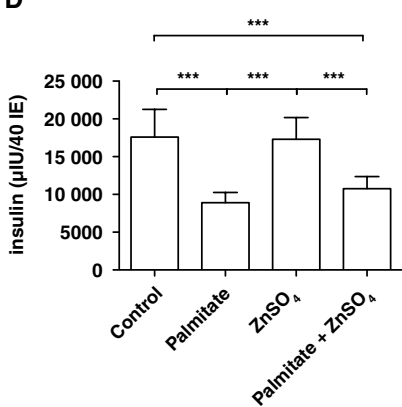

Figure 5 Zinc supplementation protected human lipotoxic islets from apoptosis but did not restore the stimulation index. (A) ATP levels, (B) apoptosis, (C) stimulation index, and (D) intracellular insulin concentration were measured in human pancreatic islets cultured in the absence or in the presence of $40 \mu \mathrm{mol} / / \mathrm{ZnSO}_{4}$ and in the absence or in the presence of $0.33 \mu \mathrm{mol} / /$ palmitate for $48 \mathrm{~h}$. Stimulation index was calculated as described in Fig. 2. Values are mean \pm S.E.M. of three different pancreases. Significant differences, ${ }^{*} P<0 \cdot 05,{ }^{* *} P<0 \cdot 01$ and ${ }^{* * *} P<0 \cdot 001$, are indicated. 
A

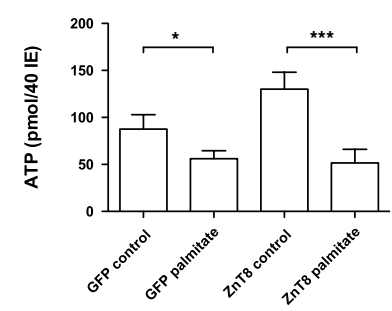

C

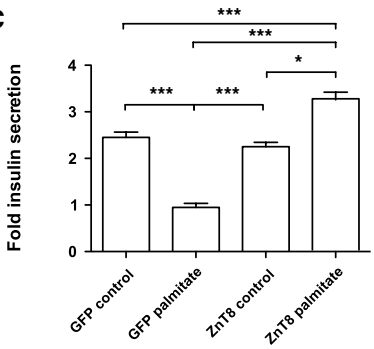

E

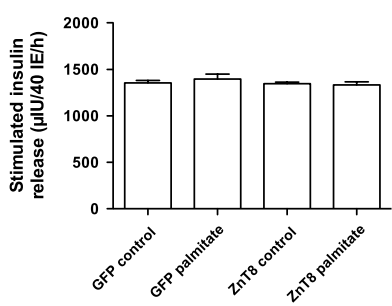

B

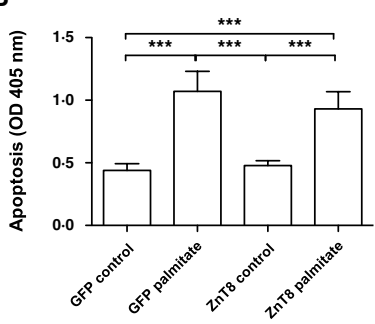

D

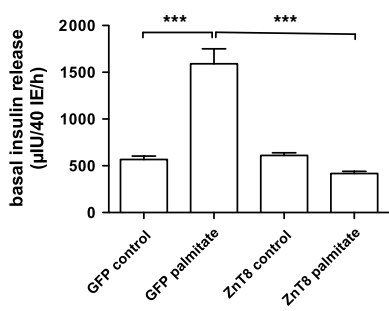

$\mathbf{F}$

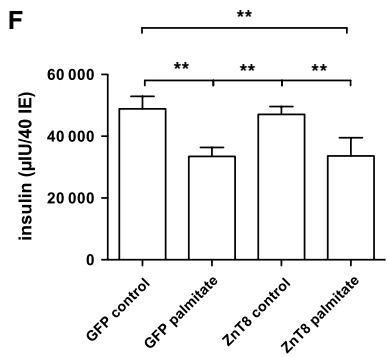

Figure 6 Overexpression of ZNT8 restored the stimulation index in human pancreatic islets subjected to lipotoxicity. (A) ATP levels, (B) apoptosis, (C) stimulation index, (D) insulin released at $2.8 \mathrm{mmol} / \mathrm{l}$ glucose for $1 \mathrm{~h}$ (basal insulin release), (E) insulin released at $20 \mathrm{mmol} / \mathrm{l}$ glucose for $1 \mathrm{~h}$ (stimulated insulin release), and $(F)$ intracellular insulin content were measured in GFP- and ZNT8-overexpressing islets cultured in the absence or in the presence of $20 \mu \mathrm{mol} / \mathrm{l}$ TPEN for $18 \mathrm{~h}$. Stimulation index was calculated as described in Fig. 2. Values are mean \pm S.E.M. of three different pancreases. Significant differences, ${ }^{*} P<0 \cdot 05,{ }^{* *} P<0 \cdot 01$ and ${ }^{* * *} P<0 \cdot 001$, are indicated.

expression and apoptosis as ZNT8-overexpressing islets were not protected from zinc chelation and lipotoxicity-induced apoptosis. In agreement with these observations, it has been shown that Znt8 knockdown in primary murine islets did not impact on apoptosis (El Muayed et al. 2010). These results are somewhat different from the previous studies performed on $\beta$-cell lines. In particular, Znt8 knockdown in INS-1E cells increased apoptosis, and Znt8 overexpression protected cells from zinc depletion-induced apoptosis while knockdown increased cell death (Chimienti et al. 2006, Petersen et al. 2011). The reason for these discrepancies remains unclear but may be related to differences in the physiology of primary islets and INS cells. We recently demonstrated that glutathione peroxidase and superoxide dismutase expressions were decreased by palmitate treatment and further suggested

that oxidative stress plays an important role in lipotoxicinduced apoptosis (Vandewalle et al. 2008). The observed effect of zinc supplementation could be related to MT induction. These proteins are an important component of the antioxidant protein pool, and they have been shown to have striking effects on the reduction of oxidative stress induced by deleterious conditions found in T2D (Yang \& Cherian 1994, Li et al. 2004, Yang et al. 2008).

We finally demonstrated a direct role of ZNT8 on regulation of basal insulin secretion. ZNT8 downregulation observed under metabolic stress was correlated with an increased basal insulin release while ZNT8 overexpression reduced it. No changes were observed in insulin content. These results are in agreement with our unpublished data demonstrating that islets isolated from Znt8-deficient mice displayed higher basal insulin release then control littermates (Supplementary Figure 2, see section on supplementary data given at the end of this article). Nicolson et al. (2009) also observed increased basal insulin release in the same model. This effect is independent of ATP levels that directly affect the exocytotic system. ATP cellular concentration decreased under metabolic stress and remained unaffected by ZNT8 overexpression (Fujimoto et al. 2002, Nabe et al. 2006). Further work is needed to elucidate the exact mechanism of how ZNT8 activity impacts insulin release but may be related to a more efficient release of noncrystalline insulin.

In conclusion, our results demonstrated i) a protective effect of zinc supplementation on human islet survival that could involve in part antioxidant activity and ii) a specific role of ZNT8 in insulin release. Its downregulation observed upon metabolic stress associated with a prediabetic state suggests that it might further contribute to T2D progression. Thus, modulating ZNT8 expression and/or activity may represent a potential therapeutic way to treat T2D.

\section{Supplementary data}

This is linked to the online version of the paper at http://dx.doi.org/10.1530/ JOE-12-0071.

\section{Declaration of interest}

The authors declare that there is no conflict of interest that could be perceived as prejudicing the impartiality of the research reported.

\section{Funding}

This work was supported by grants from Servier IdS (Suresnes, France), 'le Conseil Régional Nord-Pas de calais', University of Lille2, ANR (Safe beta) and 'Institut National de la Santé et de la Recherche Médicale' (INSERM).

\section{Acknowledgements}

The authors are indebted to R Verhaeghe, R Ezzouaoui, Laurent Arnalsteen, Adrien Sterkers, Caroline Chevalier, and the local coordination team of the 
French organ procurement agency (Agence de la Biomedecine) for pancreas procurement. The authors thank Dr Fabrice Chimienti for his kind gift of plasmid. The authors specially thank J Thevenet, N Delalleau, I Aluka, and $\mathrm{S}$ Belaich for islet isolation. The authors wish to acknowledge the skillful technical assistance of J Longue. Part of this work was made possible using equipment provided by the 'Institut Fédératif de Recherche (IFR 114)'.

\section{References}

Bancila V, Nikonenko I, Dunant Y \& Bloc A 2004 Zinc inhibits glutamate release via activation of pre-synaptic $\mathrm{K}$ channels and reduces ischaemic damage in rat hippocampus. Journal of Neurochemistry 90 1243-1250. (doi:10.1111/j.1471-4159.2004.02587.x)

Chen MD, Song YM \& Lin PY 2000 Zinc effects on hyperglycemia and hypoleptinemia in streptozotocin-induced diabetic mice. Hormone and Metabolic Research 32 107-109. (doi:10.1055/s-2007-978600)

Chimienti F, Devergnas S, Favier A \& Seve M 2004 Identification and cloning of a $\beta$-cell-specific zinc transporter, ZnT-8, localized into insulin secretory granules. Diabetes 53 2330-2337. (doi:10.2337/diabetes.53.9.2330)

Chimienti F, Devergnas S, Pattou F, Schuit F, Garcia-Cuenca R, Vandewalle B, Kerr-Conte J, Van Lommel L, Grunwald D, Favier A et al. 2006 In vivo expression and functional characterization of the zinc transporter ZnT8 in glucose-induced insulin secretion. Journal of Cell Science 119 4199-4206. (doi:10.1242/jcs.03164)

Cousins RJ, Blanchard RK, Moore JB, Cui L, Green CL, Liuzzi JP, Cao J \& Bobo JA 2003 Regulation of zinc metabolism and genomic outcomes. Journal of Nutrition 133 1521S-1526S.

Egefjord L, Jensen JL, Bang-Berthelsen CH, Petersen AB, Smidt K, Schmitz O, Karlsen AE, Pociot F, Chimienti F, Rungby J et al. 2009 Zinc transporter gene expression is regulated by pro-inflammatory cytokines: a potential role for zinc transporters in $\beta$-cell apoptosis? BMC Endocrine Disorder 9 7. (doi:10.1186/ 1472-6823-9-7)

Eide DJ 2006 Zinc transporters and the cellular trafficking of zinc. Biochimica et Biophysica Acta 1763 711-722. (doi:10.1016/j.bbamcr.2006.03.005)

El Muayed M, Billings LK, Raja MR, Zhang X, Park PJ, Newman MV, Kaufman DB, O'Halloran TV \& Lowe WL Jr 2010 Acute cytokinemediated downregulation of the zinc transporter ZnT8 alters pancreatic $\beta$-cell function. Journal of Endocrinology 206 159-169. (doi:10.1677/JOE09-0420)

Emdin SO, Dodson GG, Cutfield JM \& Cutfield SM 1980 Role of zinc in insulin biosynthesis. Some possible zinc-insulin interactions in the pancreatic B-cell. Diabetologia 19 174-182. (doi:10.1007/BF00275265)

Fu Y, Tian W, Pratt EB, Dirling LB, Shyng SL, Meshul CK \& Cohen DM 2009 Down-regulation of ZnT8 expression in INS-1 rat pancreatic $\beta$ cells reduces insulin content and glucose-inducible insulin secretion. PLOS ONE 4 e5679. (doi:10.1371/journal.pone.0005679)

Fujimoto S, Mukai E, Hamamoto Y, Takeda T, Takehiro M, Yamada Y \& Seino Y 2002 Prior exposure to high glucose augments depolarizationinduced insulin release by mitigating the decline of ATP level in rat islets. Endocrinology 143 213-221. (doi:10.1210/en.143.1.213)

Gyulkhandanyan AV, Lu H, Lee SC, Bhattacharjee A, Wijesekara N, Fox JE, MacDonald PE, Chimienti F, Dai FF \& Wheeler MB 2008 Investigation of transport mechanisms and regulation of intracellular $\mathrm{Zn}^{2+}$ in pancreatic $\boldsymbol{\alpha}$-cells. Journal of Biological Chemistry 283 10184-10197. (doi:10.1074/jbc. M707005200)

Huang L, Kirschke CP \& Gitschier J 2002 Functional characterization of a novel mammalian zinc transporter, ZnT6. Journal of Biological Chemistry 277 26389-26395. (doi:10.1074/jbc.M200462200)

Ishihara H, Maechler P, Gjinovci A, Herrera PL \& Wollheim CB 2003 Islet $\beta$-cell secretion determines glucagon release from neighbouring $\alpha$-cells. Nature Cell Biology 5 330-335. (doi:10.1038/ncb951)

Islam MS \& Loots du T 2007 Diabetes, metallothionein, and zinc interactions: a review. Biofactors 29 203-212. (doi:10.1002/biof.5520290404)

Jansen J, Karges W \& Rink L 2009 Zinc and diabetes - clinical links and molecular mechanisms. Journal of Nutritional Biochemistry 20 399-417. (doi:10.1016/j.jnutbio.2009.01.009)
Kahn SE, Hull RL \& Utzschneider KM 2006 Mechanisms linking obesity to insulin resistance and type 2 diabetes. Nature 444 840-846. (doi:10.1038/ nature05482)

Kambe T, Narita H, Yamaguchi-Iwai Y, Hirose J, Amano T, Sugiura N, Sasaki R, Mori K, Iwanaga T \& Nagao M 2002 Cloning and characterization of a novel mammalian zinc transporter, zinc transporter 5 , abundantly expressed in pancreatic $\beta$ cells. Journal of Biological Chemistry 277 19049-19055. (doi:10.1074/jbc.M200910200)

Kerr-Conte J, Vandewalle B, Moerman E, Lukowiak B, Gmyr V, Arnalsteen L, Caiazzo R, Sterkers A, Hubert T, Vantyghem MC et al. 2010 Upgrading pretransplant human islet culture technology requires human serum combined with media renewal. Transplantation 89 1154-1160. (doi:10.1097/TP. 0b013e3181d154ac)

Lefebvre B, Vandewalle B, Longue J, Moerman E, Lukowiak B, Gmyr V, Maedler K, Kerr-conte J \& Pattou F 2010 Efficient gene delivery and silencing of mouse and human pancreatic islets. BMC Biotechnology 1028. (doi:10.1186/1472-6750-10-28)

Lemaire K, Ravier MA, Schraenen A, Creemers JW, Van de Plas R, Granvik M, Van Lommel L, Waelkens E, Chimienti F, Rutter GA et al. 2009 Insulin crystallization depends on zinc transporter ZnT8 expression, but is not required for normal glucose homeostasis in mice. PNAS 106 14872-14877. (doi:10.1073/pnas.0906587106)

Li X, Chen H \& Epstein PN 2004 Metallothionein protects islets from hypoxia and extends islet graft survival by scavenging most kinds of reactive oxygen species. Journal of Biological Chemistry 279 765-771. (doi:10.1074/ jbc.M307907200)

Liuzzi JP \& Cousins RJ 2004 Mammalian zinc transporters. Annual Review of Nutrition 24 151-172. (doi:10.1146/annurev.nutr.24.012003.132402)

Liuzzi JP, Blanchard RK \& Cousins RJ 2001 Differential regulation of zinc transporter 1,2, and 4 mRNA expression by dietary zinc in rats. Journal of Nutrition 131 46-52.

Nabe K, Fujimoto S, Shimodahira M, Kominato R, Nishi Y, Funakoshi S, Mukai E, Yamada Y, Seino Y \& Inagaki N 2006 Diphenylhydantoin suppresses glucose-induced insulin release by decreasing cytoplasmic $\mathrm{H}+$ concentration in pancreatic islets. Endocrinology 147 2717-2727. (doi:10. 1210/en.2005-1260)

Nicolson TJ, Bellomo EA, Wijesekara N, Loder MK, Baldwin JM, Gyulkhandanyan AV, Koshkin V, Tarasov AI, Carzaniga R, Kronenberger K et al. 2009 Insulin storage and glucose homeostasis in mice null for the granule zinc transporter $\mathrm{ZnT} 8$ and studies of the type 2 diabetes-associated variants. Diabetes 58 2070-2083. (doi:10.2337/db09-0551)

Palmiter RD \& Findley SD 1995 Cloning and functional characterization of a mammalian zinc transporter that confers resistance to zinc. EMBO Journal 14 639-649.

Petersen AB, Smidt K, Magnusson NE, Moore F, Egefjord L \& Rungby J 2011 siRNA-mediated knock-down of ZnT3 and ZnT8 affects production and secretion of insulin and apoptosis in INS-1E cells. APMIS: Acta Pathologica, Microbiologica et Immunologica Scandinavica 119 93-102. (doi:10.1111/j.16000463.2010.02698.x)

Pound LD, Sarkar SA, Benninger RK, Wang Y, Suwanichkul A, Shadoan MK, Printz RL, Oeser JK, Lee CE, Piston DW et al. 2009 Deletion of the mouse Slc30a8 gene encoding zinc transporter-8 results in impaired insulin secretion. Biochemical Journal 421 371-376. (doi:10.1042/BJ20090530)

Roche E, Buteau J, Aniento I, Reig JA, Soria B \& Prentki M 1999 Palmitate and oleate induce the immediate-early response genes c-fos and nur-77 in the pancreatic $\beta$-cell line INS-1. Diabetes 48 2007-2014. (doi:10.2337/ diabetes.48.10.2007)

Scott LJ, Mohlke KL, Bonnycastle LL, Willer CJ, Li Y, Duren WL, Erdos MR, Stringham HM, Chines PS, Jackson AU et al. 2007 A genome-wide association study of type 2 diabetes in Finns detects multiple susceptibility variants. Science 316 1341-1345. (doi:10.1126/science.1142382)

Simon SF \& Taylor CG 2001 Dietary zinc supplementation attenuates hyperglycemia in db/db mice. Experimental Biology and Medicine 226 43-51.

Sladek R, Rocheleau G, Rung J, Dina C, Shen L, Serre D, Boutin P, Vincent D, Belisle A, Hadjadj S et al. 2007 A genome-wide association study identifies novel risk loci for type 2 diabetes. Nature 445 881-885. (doi:10.1038/ nature05616) 
Smidt K, Jessen N, Petersen AB, Larsen A, Magnusson N, Jeppesen JB, Stoltenberg M, Culvenor JG, Tsatsanis A, Brock B et al. 2009 SLC30A3 responds to glucose- and zinc variations in $\beta$-cells and is critical for insulin production and in vivo glucose-metabolism during $\beta$-cell stress. PLoS ONE 4 e5684. (doi:10.1371/journal.pone.0005684)

Tamaki M, Fujitani Y, Uchida T, Hirose T, Kawamori R \& Watada H 2009 Downregulation of $\mathrm{ZnT} 8$ expression in pancreatic $\beta$-cells of diabetic mice. Islets 1 124-128. (doi:10.4161/isl.1.2.9433)

Taylor CG 2005 Zinc, the pancreas, and diabetes: insights from rodent studies and future directions. Biometals 18 305-312. (doi:10.1007/s10534-005$3686-\mathrm{x})$

Vandewalle B, Moerman E, Lefebvre B, Defrance F, Gmyr V, Lukowiak B, Kerr Conte J \& Pattou F 2008 PPARgamma-dependent and -independent effects of rosiglitazone on lipotoxic human pancreatic islets. Biochemical and Biophysical Research Communications 366 1096-1101. (doi:10.1016/j.bbrc. 2007.12.088)

Vantyghem MC, Kerr-Conte J, Arnalsteen L, Sergent G, Defrance F, Gmyr V, Declerck N, Raverdy V, Vandewalle B, Pigny P et al. 2009 Primary graft function, metabolic control, and graft survival after islet transplantation. Diabetes Care 32 1473-1478. (doi:10.2337/dc08-1685)

Wijesekara N, Dai FF, Hardy AB, Giglou PR, Bhattacharjee A, Koshkin V, Chimienti F, Gaisano HY, Rutter GA \& Wheeler MB 2010 B Cell-specific
Znt8 deletion in mice causes marked defects in insulin processing, crystallisation and secretion. Diabetologia 53 1656-1668. (doi:10.1007/ s00125-010-1733-9)

Yang J \& Cherian MG 1994 Protective effects of metallothionein on streptozotocin-induced diabetes in rats. Life Sciences $\mathbf{5 5} 43-51$. (doi:10.1016/0024-3205(94)90080-9)

Yang L, Li H, Yu T, Zhao H, Cherian MG, Cai L \& Liu Y 2008 Polymorphisms in metallothionein-1 and -2 genes associated with the risk of type 2 diabetes mellitus and its complications. American Journal of Physiology. Endocrinology and Metabolism 294 E987-E992. (doi:10.1152/ ajpendo.90234.2008)

Zeggini E, Weedon MN, Lindgren CM, Frayling TM, Elliott KS, Lango H, Timpson NJ, Perry JR, Rayner NW, Freathy RM et al. 2007 Replication of genome-wide association signals in UK samples reveals risk loci for type 2 diabetes. Science 316 1336-1341. (doi:10.1126/science.1142364)

\section{Received in final form 17 April 2012 \\ Accepted 11 May 2012}

Made available online as an Accepted Preprint

11 May 2012 